\title{
Teen clinics: missing the mark? Comparing pregnancy and sexually transmitted infections rates among enrolled and non-enrolled adolescents
}

Souradet Y. Shaw ${ }^{1,2^{*}}$, Colleen Metge ${ }^{2,3}$, Carole Taylor ${ }^{4}$, Mariette Chartier ${ }^{4}$, Catherine Charette ${ }^{3}$, Lisa Lix ${ }^{2,3,4}$, Rob Santos ${ }^{4,5}$, Joykrishna Sarkar ${ }^{4}$, Nathan C. Nickel ${ }^{4}$, Elaine Burland ${ }^{4}$, Dan Chateau ${ }^{4}$, Alan Katz ${ }^{4}$, Marni Brownell ${ }^{4}$, Patricia J. Martens and the PATHS Equity Team

\begin{abstract}
Background: In Manitoba, Canada, school-based clinics providing sexual and reproductive health services for adolescents have been implemented to address high rates of sexually transmitted infections (STIS) and pregnancies.

Methods: The objectives of this population-based study were to compare pregnancy and STI rates between adolescents enrolled in schools with school-based clinics, those in schools without clinics, and those not enrolled in school. Data were from the PATHS Data Resource held in the Population Health Research Data Repository housed at the Manitoba Centre for Health Policy. Adolescents aged 14 to 19 between 2003 and 2009 were included in the study. Annualized rates of pregnancies and positive STI tests were estimated and Poisson regression models were used to test for differences in rates amongst the three groups.
\end{abstract}

Results: As a proportion, pregnancies among non-enrolled female adolescents accounted for $55 \%$ of all pregnancies in this age group during the study period. Pregnancy rates were 2-3 times as high among non-enrolled female adolescents. Compared to adolescents enrolled in schools without school-based clinics, age-adjusted STI rates were 3.5 times $(p<.001)$ higher in non-enrolled males and 2.3 times $(p<.001)$ higher in non-enrolled females.

Conclusions: The highest rates for pregnancies and STls were observed among non-enrolled adolescents. Although provision of reproductive and health services to in-school adolescents should remain a priority, program planning and design should consider optimal strategies to engage out of school youth.

Keywords: School-based clinics, Teen pregnancies, STIs, Out of school youth

\section{Implications and contribution}

Results demonstrate that the highest rates for pregnancies and STIs were observed among non-enrolled adolescents. Parallel strategies to engage out of school youth may potentially impact population-level rates of pregnancies and STIs.

\footnotetext{
* Correspondence: umshaw@myumanitoba.ca

'Deceased

${ }^{1}$ Centre for Global Public Health, University of Manitoba, Winnipeg, Canada

${ }^{2}$ Department of Community Health Sciences, University of Manitoba,

Winnipeg, Canada

Full list of author information is available at the end of the article
}

\section{Background}

In North America, the majority of adolescents have experienced sexual intercourse by the time they have reached adulthood $[1,2]$. Fostering positive views on sexuality is an important component of development for adolescents as they transition into adulthood; high rates of sexually transmitted infections (STIs) and unwanted pregnancies among adolescents highlight the need for preventive education and health services targeting sexually active adolescents [3-5].

For many adolescents, the school is one of the main sources of information regarding reproductive and 
sexual health. Consequently, in North America, schoolbased reproductive and sexual health clinics ("schoolbased clinics") have been promoted as a means to deliver health services to adolescents in an accessible manner $[6,7]$. However, the literature on the real-world effectiveness of school-based clinics has been mixed, with improvements demonstrated in self-efficacy and knowledge, but not necessarily in actual behaviours $[8,9]$. Identification of barriers to and facilitators of access to school-based clinics by adolescents has provided fertile ground for research, with socioeconomic status, perceived need, comfort level with staff, physical location, and confidentiality cited as factors influencing the choice to access care $[10,11]$.

With the increasing focus on school-based clinics, however, there has been less of an emphasis on outof-school adolescents. Adolescents not engaged in traditional school settings, such as "street-involved youth" (a broad term used to describe youth living or working on the streets) often have disproportionately high rates of STIs [12, 13]. One national study of Canadian street-involved youth found that the relative prevalence of both chlamydia and gonorrhea were 10 and over 20 times higher, respectively, compared with non-street-involved youth [13]. Similarly, engagement with school has been shown to be an important factor in postponing pregnancy [14].

Although these studies suggest that adolescents not enrolled in school may be at higher risk for STIs and early pregnancy, much of the literature on adolescent reproductive health is limited to individuals enrolled in school. Indeed, much of the seminal work in adolescent health uses data where the primary point of contact was in the school. This is because adolescents not enrolled in school are hard to reach and are often missed in adolescent health studies. Limited research exists that directly compares the reproductive health outcomes between inschool adolescents and those not enrolled in school.

In Manitoba, school-based clinics providing adolescent health services are located in community health centres, schools and one hospital. At the time of this study, there were 7 school-based clinics in Winnipeg (the province's capital city, constituting over half of the province's total population), and 8 school-based clinics in the province's rural and northern areas. As part of the criteria for the receipt of funding, schools desiring clinics were asked to justify the need for the clinic, with funding allocated to those schools most "at need". It is of note that the school-based clinics vary in terms of program characteristics. For example, while all clinics provide free birth control pills, only some provide free contraceptive shots or patches. Some school-based clinics serve high school students while some also middle school students. Also, hours of operation vary widely. At the time of this study, there were 20 clinics located in the community that served both enrolled and non-enrolled adolescents (15 in Winnipeg; 5 in rural and northern areas).

Given the unique opportunity in Manitoba to capture health information on adolescents not enrolled in school, our research objectives were to compare pregnancy and positive STI rates between three groups: adolescents enrolled in schools with school-based clinics, adolescents enrolled in schools without school-based clinics and adolescents who were not enrolled in school. We hypothesized that (1) adolescents not enrolled in school will have higher STI and pregnancy rates than inschool-adolescents, as pregnancy has been shown to be associated with school drop out; and (2) that STI and pregnancy rates in schools with clinics will be higher (lower) than schools without clinics, as clinics were likely located in schools in "higher needs" areas. This study was conducted as part of the PATHS Equity Program of Research, a research program aimed at understanding mechanisms to reduce child health inequity [15].

\section{Methods \\ Data sources}

The data for this study are from the PATHS Data Resource held in the Population Health Research Data Repository (the Repository) housed at the Manitoba Centre for Health Policy (MCHP) at the University of Manitoba. The PATHS Resource comprises approximately $99 \%$ of all individuals living in Manitoba, born 1984 to 2012. The Resource includes individual-level health, education and social services administrative data that were originally collected to manage and monitor services. These data contain almost all contacts Manitoba residents have with provincial services throughout childhood, from the prenatal period through to adulthood. The PATHS Resource does not hold personal identifying information, such as names and addresses, but rather an anonymized, scrambled numeric identifier can be used to link individual-level data across files and over time. Thus, researchers are able to construct holistic child health and development trajectories for nearly all children residing in Manitoba. Numerous studies have validated the data within the Resource for research purposes [16-21] and other studies have been published which specifically used the PATHS Resource, to study child health equity [22-24].

The specific data files used in the analyses were:

1. Manitoba Health Insurance Registry, which captures all Manitobans eligible to receive health services and includes demographic information and 6-digit residential postal code for geocoding. Universal health care coverage is offered in Manitoba from a single insurer; 
2. Hospital Abstracts, which contain information on all hospitalizations (including birth) in Manitoba and which include up to 16 ICD-9-CM diagnostic codes for discharges before April 1, 2004 and up to 25 ICD10-CA diagnostic codes for discharges on or after April 1, 2004;

3. Medical Services, which contain information on ambulatory physician visits in Manitoba and include a single ICD-9 diagnostic code associated with each visit, coded to the third digit.

4. Cadham Provincial Laboratory, which provides a range of services, including public health laboratory services and reference services for identification and typing of microorganisms (microbiology, serology and parasitology, and virology); requisition/result level data are available at the individual patient level and include clinical information (travel/treatment history, signs and symptoms, specimen information, and reason for test);

5. Statistics Canada Census information, which is used to determine area-level income, with the Manitoba population divided into income quintiles according to average area-level household income, comprising 5 income groupings;

6. Social Assistance and Management Information Network, which includes information on all individuals and families receiving provincial Employment and Income Assistance;

7. Child and Family Services Information system, which include information on all Manitoba children and their families receiving child welfare services, including in-home services and out-of-home placements;

8. Education data, which include Enrollment, Marks and Assessment data for all high school students in Manitoba schools including information on special education needs and funding.

\section{Study population}

The study population consisted of all adolescents (male and female) aged 14 to 19 years of age, who were either enrolled in grades 9 to 12 (or identified as special needs students at a high school level) or not, with continuous health coverage between fiscal years (April 1 to March 31) 2003 to $2010(N=181,444)$. Our study population was divided into three groups: (1) adolescents categorized as not enrolled in school ("non-enrolled", $N=32,067$ ), (2) adolescents enrolled in schools that contained a school clinic (SC, $N=26,223$ ), and (3) adolescents enrolled in schools without a school clinic (NSC, $N=123,154)$. Adolescents enrolled in school were identified by the enrolment dataset. A list of schools with clinics was provided in consultation with the Healthy Child Manitoba Office. Adolescents enrolled in schools on this list were classified as attending a school with a SC. Teenagers classified as not enrolled in school were those with no enrolment record in a given year, excluding students graduating in the year of interest, or in the years prior to the year of interest. Students in schools that did not have Grade 12 were also excluded, as their inclusion was thought to potentially bias comparisons, given that sexual activity is known to increase as adolescents age, with those in Grade 12 being the most likely to engage in sexual activity [25]. Furthermore, as the published evidence of older adolescents partnering with younger adolescents is strong $[26,27]$, it was thought that the network dynamics of schools without Grade 12 students could potentially differ greatly from those with Grade 12 students, as they exclude the group most likely to be engaged in sexual activity. Finally, students who transferred schools mid-year were excluded because allocation to one school was not possible; less than $2 \%$ of students transferred mid-year, so the potential impact on results was thought to be minimal.

\section{Outcome measures \& rate calculations Teenage pregnancy \& positive STI tests}

Pregnancies were defined with a previously published administrative case definition using hospital abstracts [28, 29]. Additional file 1: Table S1 contains the ICD codes (including diagnoses and procedure codes) used to define pregnancies. As all STI tests are performed at the Cadham Provincial Laboratory we were able to define positive STI cases as positive laboratory tests for chlamydia, gonorrhea or syphilis.

\section{Statistical analyses \\ Rates}

Each outcome of interest was used as the numerator for rate calculations. Denominators were the midpoint population of each corresponding one-year age band for the year in question; for pregnancy, only females were included, while for STI tests, both males and females were included. Rates were stratified by group (i.e., SC, NSC and non-enrolled), and crude pregnancy and STI rates were generated, along with their $95 \%$ confidence intervals (95\% CIs). Rates were also age-adjusted using a generalized linear modelling approach with a Poisson distribution selected, with age (and its quadratic term) and enrolment status entered as covariates, with the entire cohort population used as the standard [30]. Except where indicated, age-adjusted rates are reported. Rates were age-adjusted due to the differences in age structure between the three groups of interest. Rates were not adjusted for income quintile (i.e., an indicator of socioeconomic status) as in this instance, socio-economic status likely acts as an effect modifier, rather than a confounder. To address this, the association between 
enrolment status and the outcome variables were stratified by income quintile.

The groups were compared on a number of sociodemographic and school-related variables. For the purposes of this comparison, information from adolescents in the 2008/09 academic year is presented. The following variables were used in the descriptive analysis: age (in years), sex, current grade, Grade 9 Performance Index, region, income quintile, receipt of income assistance, currently receiving child welfare services, and history of receiving child welfare services. The Grade 9 Performance Index is a standardized, scaled logit measure developed by MCHP researchers that measures the academic performance of students in grade 9, relative to their peers [31]. The Performance Index is calculated using all possible average marks in all classes and the number of credits earned during the grade 9 school year; higher scores on the Index translate to better performance in grade 9. The Index ranged from -2.5 to 2.3 in our cohort. Region was classified into the five Manitoba Regional Health Authorities: Interlake-Eastern, Northern, Eastern, Prairie Mountain and Winnipeg. Similar to previous research, Winnipeg was further divided into three regions by aggregate health status: most, least and average health status [32]. Health status was determined by premature mortality at the neighbourhood cluster (an administrative unit used by the Winnipeg Regional Health Authority) level. Income quintile, an area-level measure of household income based on Statistics Canada dissemination areas, was derived by dividing the population of Manitoba into 5 income groups, so that $20 \%$ of the population is in each group [33]. Receipt of income assistance measures whether or not the individual, or the individual's family (if under the age of 18) was currently receiving income assistance. Finally, current and historic involvement with child welfare services measures whether or not the adolescent is in or has been in out-of-home care or their family is currently or has historically received protection or support services from the child welfare system in Manitoba [34].

Rates were estimated for groups and income quintiles within groups using a generalized linear model with a Poisson distribution. Relative risks (RR) and $95 \%$ CIs are reported. Model fit was assessed using the ratio of the deviance to the model degrees of freedom; a value close to one indicates a well-fitting model. All analyses were performed using $\mathrm{SAS}^{\circ}$ version 9.3. As this was a study based on de-identified administrative data, informed consent was not obtained. This study was approved by the Health Research Ethics Board at the University of Manitoba and the Health Information Privacy Committee of Manitoba.

\section{Results}

Socio-demographic characteristics in 2008

The socio-demographic and school related characteristics for adolescents for the three groups in academic year 2008/09 are displayed in Table 1. There were substantial differences in age structure between the three groups; over $50 \%$ of the non-enrolled group was composed of 18 and 19 year olds, compared to approximately $10 \%$ of both the SC and NSC groups. The nonenrolled group also scored lower on the Grade 9 Performance Index, relative to the SC and NSC groups, and were the most likely to reside $(40 \%)$ in an area in the lowest income quintile, currently receiving child welfare services $(4.5 \%)$, and have a history of involvement with child welfare services (41\%).

The remaining results section focuses on the 181,444 adolescents included in the multiple years available for this study, of which $14 \%(26,223 / 181,444)$ were SC, $68 \%(123,154 / 181,444)$ were NSC and $18 \%(32,067 /$ 181,444) were non-enrolled youth.

\section{Pregnancy}

From 2003 to 2009 a total of 9,292 pregnancies were recorded in the cohort of adolescent females, with over $55 \%(5,140 / 9,292)$ occurring among those in the nonenrolled group (Table 2). Pregnancies in SC females aged 14 to 19 accounted for approximately $10 \%$ of all pregnancies in the sample during this time period, for an age-adjusted pregnancy rate for SC females aged 14 to 19 of 42.8 per 1000 . The pregnancy rate for NSC females was 31.8 per 1,000 and 87.9 per 1,000 for those females not enrolled. The rate for non-enrolled females was 2.1 times $(p<.0001)$ higher than SC females and 2.8 times $(p<.0001)$ higher than NSC females (Table 3). Crude rates and relative rates by income quintile are available in Additional file 1: Tables S2 and S3.

\section{Income quintile}

Regardless of school clinic or enrollment status, a steep gradient, by income quintile, was observed in pregnancy rates (Table 4). Generally speaking, low-income areas had the highest pregnancy rates, while the lowest pregnancy rates were observed in high-income areas. At 134.4 per 1,000, the highest pregnancy rate was observed among non-enrolled females from the lowest income quintile areas (i.e., Q1 residents). Among Q1 residents, the pregnancy rate for non-enrolled females was 1.7 times $(p<.0001)$ higher than SC females and 2.0 times $(p<.0001)$ higher than NSC females (Table 5).

\section{STIs}

From 2003 to 2009 , a total of 4,297 positive STI tests were reported for the cohort of adolescents for an overall rate of 12.1 per 1,000 (Table 2). At 16.5 per 
Table 1 Select socio-demographic and school-related characteristics, youth and adolescents from schools with and without school clinic access and non-enrolled status, 2008/09 academic year $(N=66,539)$

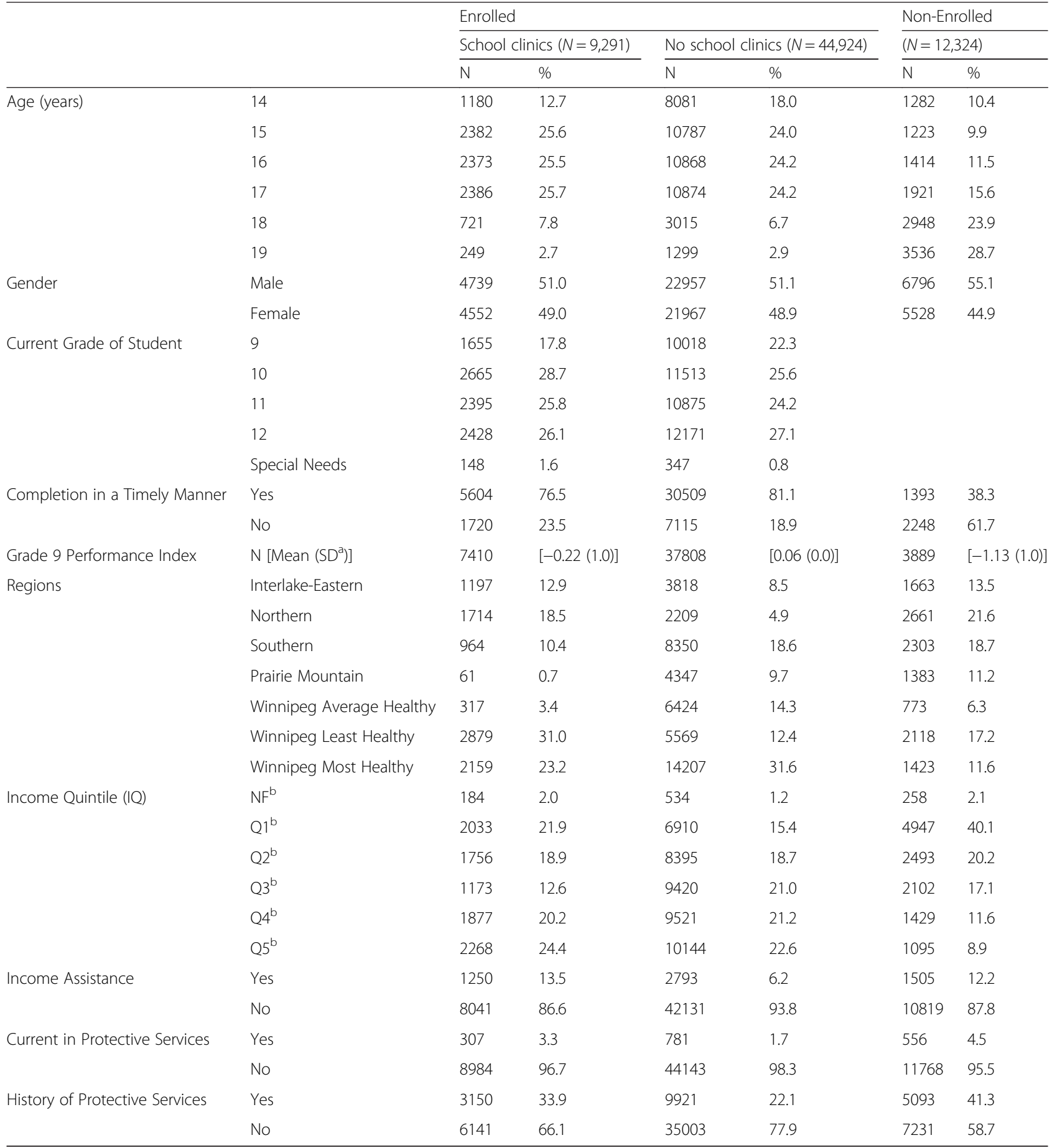

${ }^{\mathrm{a}} \mathrm{S} D$ standard deviation, ${ }^{\mathrm{b}} \mathrm{NF}$ not found, Q1 quintile 1 (lowest income quintile), Q2 quintile 2, Q3 quintile 3, Q4 quintile 5 (highest income quintile)

1,000 , female rates were over twice as high as male rates (7.8 per 1,000). Approximately $48 \%(2,047 /$ 4,297 ) of all STIs were reported from members of the non-enrolled group. STI rates were highest in the non-enrolled group for both males $(14.3$ per 1,000$)$ and females (23.9 per 1,000), and lowest in the NSC group. Compared to the NSC group, the adjusted rate in the non-enrolled group was 3.5 times $(p<.0001)$ higher in males, and 2.3 times $(p<.0001)$ higher in females (Table 3). 
Table 2 Crude and age-adjusted pregnancy and sexually transmitted infections rates, by enrolled/non-enrolled group, 2000-2009

\begin{tabular}{|c|c|c|c|c|}
\hline & School clinic (SC) & No school clinic (NSC) & Non-Enrolled & Total \\
\hline \multicolumn{5}{|l|}{ Pregnancy } \\
\hline No. & 939 & 3213 & 5140 & 9292 \\
\hline Crude rate (per 1,000 ) & $35.8(33.5-38.1)$ & $26.1(25.2-27.0)$ & $160.3(155.9-164.7)$ & $51.2(50.2-52.3)$ \\
\hline Age-adjusted & $42.8(40.0-45.8)$ & $31.8(30.5-33.1)$ & $87.9(84.8-91.1)$ & $53.3(52.2-54.5)$ \\
\hline \multicolumn{5}{|l|}{ STIS } \\
\hline \multicolumn{5}{|l|}{ Female } \\
\hline No. & 467 & 1134 & 1112 & 2713 \\
\hline Crude rate (per 1,000 ) & $17.8(16.2-19.4)$ & $9.2(8.7-9.7)$ & $34.7(32.6-36.7)$ & $15.0(14.4-15.5)$ \\
\hline Age-adjusted & $19.5(17.7-21.5)$ & $10.2(9.5-11.0)$ & $23.9(22.2-25.7)$ & $16.5(15.9-17.1)$ \\
\hline \multicolumn{5}{|l|}{ Male } \\
\hline No. & 200 & 449 & 935 & 1584 \\
\hline Crude rate (per 1,000 ) & $7.1(6.1-8.1)$ & $3.5(3.1-3.8)$ & $23.3(21.8-24.7)$ & $8.0(7.6-8.4)$ \\
\hline Age-adjusted & $8.3(7.1-9.6)$ & $4.1(3.7-4.6)$ & $14.3(13.1-15.6)$ & $7.8(7.4-8.3)$ \\
\hline \multicolumn{5}{|l|}{ Total } \\
\hline No. & 667 & 1583 & 2047 & 4297 \\
\hline Crude rate (per 1,000) & $12.3(11.3-13.2)$ & $6.3(5.9-6.6)$ & $28.3(27.1-29.6)$ & $11.3(11.0-11.7)$ \\
\hline Age-adjusted & $13.7(12.6-14.9)$ & $7.1(6.7-7.5)$ & $18.9(17.9-20.0)$ & $12.1(11.7-12.5)$ \\
\hline
\end{tabular}

\section{Income quintile}

Similar to pregnancy rates, a gradient was observed by income quintile, with the highest STI rates in the lowest income quintile areas, and the lowest STI rates in the highest income areas (Table 4). Generally speaking, a statistically significant increase in rates was observed when comparing the non-enrolled group to the SC and NSC groups, even when stratified by income quintile (Table 5), and by sex. For example, among males living in areas with the lowest income (i.e., Q1), positive STI tests were 2.1 times $(p<.0001)$ higher in the non-enrolled group, compared to the NSC group. Of some interest, and for both pregnancy and STIs, the discrepancy between non-enrolled youth and either SC or NSC youth increased as a function of income quintile.

\section{Discussion}

Our results demonstrate that the highest rates of pregnancy and STIs were found among youth not enrolled in schools. Compared to youth enrolled in schools without clinics, youth not enrolled in schools had almost three times the rate of pregnancies and STIs. The higher rates

Table 3 Relative Rates (RR) and $95 \%$ confidence intervals (95\% Cl) of Crude and Age-adjusted Rates, Non-enrolled group

\begin{tabular}{|c|c|c|c|c|c|}
\hline & $\operatorname{RR}(95 \% \mathrm{Cl})$ & & $\operatorname{RR}(95 \% \mathrm{Cl})$ & & $\mathrm{RR}(95 \% \mathrm{Cl})$ \\
\hline \multicolumn{6}{|l|}{ Pregnancy } \\
\hline Non-enrolled vs. SC ${ }^{a}$ (crude) & $4.5(4.2-4.8)$ & Non-enrolled vs. NSC ${ }^{a}$ (crude) & $6.1(5.9-6.4)$ & SC vs. NSC ${ }^{a}$ (crude) & $1.4(1.3-1.5)$ \\
\hline Non-enrolled vs. SC (adjusted) & $2.1(1.9-2.2)$ & Non-enrolled vs. NSC ${ }^{a}$ (adjusted) & $2.8(2.6-2.9)$ & SC vs. NSC ${ }^{a}$ (adjusted) & $1.3(1.3-1.4)$ \\
\hline \multicolumn{6}{|l|}{ STIs } \\
\hline \multicolumn{6}{|l|}{ Female } \\
\hline Non-enrolled vs. SC ${ }^{a}$ (crude) & $1.9(1.7-2.2)$ & Non-enrolled vs. NSC ${ }^{a}$ (crude) & $3.8(3.5-4.1)$ & SC vs. NSC ${ }^{a}$ (crude) & $1.9(1.7-2.2)$ \\
\hline Non-enrolled vs. SC ${ }^{a}$ (adjusted) & $1.2(1.1-1.4)$ & Non-enrolled vs. NSC ${ }^{a}$ (adjusted) & $2.3(2.1-2.6)$ & SC vs. NSC ${ }^{a}$ (adjusted) & $1.9(1.7-2.1)$ \\
\hline \multicolumn{6}{|l|}{ Male } \\
\hline Non-enrolled vs. SC (crude) & $3.3(2.8-3.8)$ & Non-enrolled vs. NSC ${ }^{a}$ (crude) & $6.7(6.0-7.5)$ & SC vs. NSC ${ }^{a}$ (crude) & $2.1(1.7-2.4)$ \\
\hline Non-enrolled vs. SC (adjusted) & $1.7(1.5-2.0)$ & Non-enrolled vs. NSC ${ }^{a}$ (adjusted) & $3.5(3.1-3.9)$ & SC vs. NSC ${ }^{a}$ (adjusted) & $2.0(1.7-2.4)$ \\
\hline \multicolumn{6}{|l|}{ Total } \\
\hline Non-enrolled vs. SC (crude) & $2.3(2.1-2.5)$ & Non-enrolled vs. NSC (crude) & $4.5(4.2-4.8)$ & SC vs. NSC ${ }^{a}$ (crude) & $2.0(1.8-2.2)$ \\
\hline Non-enrolled vs. SC (adjusted) & $1.4(1.3-1.5)$ & Non-enrolled vs. NSC ${ }^{a}$ (adjusted) & $2.7(2.5-2.9)$ & SC vs. NSC ${ }^{a}$ (adjusted) & $1.9(1.7-2.2)$ \\
\hline
\end{tabular}

${ }^{\mathrm{a} S C}$ schools with clinics, NSC schools without clinics 
Table 4 Age-adjusted pregnancy and sexually transmitted infections rates per 1000 teens ages 15-19, by enrolled/non-enrolled group and income quintile, 2000-2009

\begin{tabular}{|c|c|c|c|c|}
\hline $\begin{array}{l}\text { Neighbourhood income } \\
\text { quintile }\end{array}$ & $\begin{array}{l}\text { Age-adjusted rate per } 1000 \\
\text { School Clinic (SC) }\end{array}$ & $\begin{array}{l}\text { Age adjusted rate per } 1000 \\
\text { No School Clinic (NSC) }\end{array}$ & $\begin{array}{l}\text { Age-adjusted rate per } 1000 \\
\text { Non-Enrolled }\end{array}$ & $\begin{array}{l}\text { Overall age-adjusted rate per } 1000 \\
\text { Total }\end{array}$ \\
\hline \multicolumn{5}{|l|}{ Pregnancy $^{a}$} \\
\hline Q1 (lowest) & 76.8 (69.7-84.6) & $66.9(63.3-70.8)$ & 134.4 (129.2-139.9) & 99.39 (96.37-102.51) \\
\hline Q2 & $44.4(38.2-51.6)$ & $38.8(36.1-41.7)$ & $96.5(90.8-102.5)$ & $58.60(56.07-61.23)$ \\
\hline Q3 & $34.4(28.1-42.2)$ & $28.1(25.8-30.5)$ & 78.5 (72.5-85.0) & $41.70(39.47-44.04)$ \\
\hline Q4 & $32.8(27.7-38.8)$ & $20.3(18.4-22.3)$ & 57.5 (51.8-63.8) & 29.67 (27.79-31.67) \\
\hline Q5 (highest) & $24.3(20.5-28.9)$ & $11.7(10.3-13.3)$ & $51.1(45.1-57.9)$ & $20.18(18.66-21.84)$ \\
\hline \multicolumn{5}{|l|}{ STIS $s^{a}$} \\
\hline \multicolumn{5}{|l|}{ Female } \\
\hline Q1 (lowest) & $43.4(38.2-49.4)$ & $25.2(23.0-27.7)$ & $42.2(39.0-45.6)$ & 34.5 (32.7-36.4) \\
\hline Q2 & $20.2(16.2-25.1)$ & $14.3(12.7-16.0)$ & $27.5(24.2-31.2)$ & 18.5 (17.1-20.0) \\
\hline Q3 & $12.5(9.0-17.4)$ & $7.9(6.8-9.2)$ & $16.8(13.8-20.4)$ & $10.1(9.0-11.3)$ \\
\hline Q4 & $11.7(8.9-15.4)$ & $6.0(5.0-7.1)$ & $13.0(10.1-16.7)$ & $7.9(6.9-8.9)$ \\
\hline Q5 (highest) & $11.1(8.7-14.1)$ & $3.6(2.9-4.5)$ & $10.9(8.0-14.8)$ & $5.8(5.0-6.7)$ \\
\hline \multicolumn{5}{|l|}{ Male } \\
\hline Q1 (lowest) & $18.0(14.8-21.8)$ & 11.6 (10.2-13.3) & $24.0(22.0-26.3)$ & $18.3(17.1-19.7)$ \\
\hline Q2 & $8.7(6.4-11.8)$ & $5.2(4.3-6.2)$ & $13.4(11.5-15.5)$ & $8.5(7.6-9.4)$ \\
\hline Q3 & $5.8(3.7-9.0)$ & $2.2(1.7-2.9)$ & $9.4(7.7-11.6)$ & $4.5(3.8-5.2)$ \\
\hline Q4 & $3.6(2.3-5.8)$ & $1.4(1.0-1.9)$ & $7.3(5.7-9.4)$ & $3.0(2.5-3.6)$ \\
\hline Q5 (highest) & $2.9(1.8-4.6)$ & $1.2(0.9-1.8)$ & $6.9(5.1-9.2)$ & $2.5(2.1-3.1)$ \\
\hline
\end{tabular}

${ }^{a}$ Q1 quintile 1 (lowest income quintile), Q2 quintile 2, Q3 quintile 3, Q4 quintile 5 (highest income quintile)

observed in non-enrolled youth were observed even after stratifying by area-level wealth, although the association was more pronounced for pregnancy and STIs among males. As part of the criteria for the receipt of funding, schools desiring clinics were asked to justify the need for the clinic, with funding allocated to those schools most "at need". Thus, high-risk schools were targeted by the school-based clinic program, consistent with recommendations from the literature [35]. To the best of our knowledge, ours is the first population-based study to explicitly compare rates of pregnancy and STIs among youth not enrolled in schools, to those youth enrolled in schools with, and without school-based clinics in Canada. The results from this study suggest program implementers were successful in their targeting efforts, as among those enrolled in schools, youth from schools with clinics were at highest need, irrespective of indicator examined. At the same time, our results indicate that out-of-school youth accounted for the majority of teen pregnancies and STIs. Thus, taken together, these results stress the urgent need for prevention and intervention services aimed at out-of-school youth, alongside strategies that provide accessible care to youth attending schools.

Generally speaking, the finding that youth who were not enrolled in school had the poorest outcomes in our study is consistent with the literature [14, 36]. Among a sample of high-risk African American girls, Crosby et al. demonstrated that girls who dropped out of school were two times as likely to test positive for STIs (specifically, Trichomonas vaginalis and/or Chlamydia trachomatis), compared to those who remained enrolled in school [36]. It should be noted that some studies have demonstrated evidence of school-based clinics being effective in producing positive academic outcomes [37], including improving attendance, and modest reductions in school dropout rates among moderate users of school clinics [37-39]. Moreover, research has shown that even among those already pregnant, the provision of prenatal care reduced school absenteeism and dropout rates [40]. Given evidence suggesting consistent school attendance as a protective factor in reducing adolescent pregnancies [14], the provision of school-based health care can potentially work in a preventative manner to delay or reduce school dropout rates, and can also work in concert with other services that more formally target out-ofschool youth, ultimately providing a comprehensive set of services for youth. In terms of policy implications, although the focus of funding in Manitoba was for schoolbased health clinics, our findings suggest that to see an impact at the population level, programs that engage out-of-school youth through outreach and/or tailored 
Table 5 Relative Rates (RR) and $95 \%$ confidence intervals (95\% $\mathrm{Cl}$ ), non-enrolled youth, vs. SC and NSC youth, by income quintile (age-adjusted)

\begin{tabular}{|c|c|c|}
\hline & $\begin{array}{l}\text { RR of non-enrolled } \\
\text { vs. School Clinic (SC) } \\
\text { as reference }\end{array}$ & $\begin{array}{l}\text { RR of non-enrolled vs. } \\
\text { No School Clinic (NSC) } \\
\text { as reference }\end{array}$ \\
\hline \multicolumn{3}{|l|}{ Pregnancy $^{a}$} \\
\hline RR (95 \% Cl): Q1 & $1.7(1.6-1.9)$ & $2.0(1.9-2.1)$ \\
\hline RR (95 \% Cl): Q2 & $2.2(1.8-2.5)$ & $2.5(2.3-2.7)$ \\
\hline RR (95 \% Cl): Q3 & $2.3(1.8-2.8)$ & $2.8(2.5-3.1)$ \\
\hline RR (95 \% Cl): Q4 & $1.8(1.4-2.2)$ & $2.9(2.5-3.3)$ \\
\hline RR (95 \% Cl): Q5 & $2.1(1.7-2.6)$ & $4.4(3.7-5.3)$ \\
\hline \multicolumn{3}{|l|}{ STIs ${ }^{a}$} \\
\hline \multicolumn{3}{|l|}{ Female } \\
\hline RR (95 \% Cl): Q1 & $1.0(0.8-1.1)$ & $1.7(1.5-1.9)$ \\
\hline RR (95 \% Cl): Q2 & $1.4(1.1-1.8)$ & $1.9(1.6-2.3)$ \\
\hline RR (95 \% Cl): Q3 & $1.3(0.9-2.0)$ & $2.1(1.7-2.7)$ \\
\hline RR (95 \% Cl): Q4 & $1.1(0.8-1.6)$ & $2.2(1.6-3.0)$ \\
\hline RR (95 \% Cl): Q5 & $1.0(0.7-1.5)$ & $3.0(2.1-4.4)$ \\
\hline \multicolumn{3}{|l|}{ Male } \\
\hline RR (95 \% Cl): Q1 & $1.3(1.1-1.7)$ & $2.1(1.8-2.4)$ \\
\hline RR (95 \% Cl): Q2 & $1.5(1.1-2.2)$ & $2.6(2.0-3.3)$ \\
\hline RR (95 \% Cl): Q3 & $1.6(1.0-2.7)$ & $4.3(3.0-6.0)$ \\
\hline RR (95 \% Cl): Q4 & $2.0(1.2-3.4)$ & $5.3(3.5-8.0)$ \\
\hline RR (95 \% Cl): Q5 & $2.4(1.4-4.1)$ & $5.5(3.5-8.8)$ \\
\hline \multicolumn{3}{|l|}{ Total } \\
\hline RR (95 \% Cl): Q1 & $1.1(1.0-1.2)$ & $1.8(1.6-2.0)$ \\
\hline RR (95 \% Cl): Q2 & $1.4(1.2-1.7)$ & $2.1(1.8-2.4)$ \\
\hline RR (95 \% Cl): Q3 & $1.5(1.1-2.0)$ & $2.6(2.2-3.2)$ \\
\hline RR (95 \% Cl): Q4 & $1.3(1.0-1.8)$ & $2.8(2.2-3.6)$ \\
\hline RR (95 \% Cl): Q5 & $1.3(1.0-1.7)$ & $3.7(2.8-5.0)$ \\
\hline
\end{tabular}

${ }^{a}$ Q1 quintile 1 (lowest income quintile), Q2 quintile 2, Q3 quintile 3, Q4 quintile 5 (highest income quintile)

programming need also be considered alongside schoolbased clinics. Moreover, in addition to medical services, there is also potential for the school-based clinics to either develop, or partner with organizations that offer other services, such as prenatal care.

Our study has a number of strengths. By using population-based data on nearly all adolescents, we were able to include individuals from marginalized populations which are frequently not captured using survey data (15; 17-20); this increases the generalizability of our findings vis-à-vis health equity research. Using administrative data allowed us to both leverage objective measures of the outcomes used in the study and avoid the problems associated with recall bias (18-20). In spite of the several strengths of our study, there are limitations worth noting. Although we were able to adjust for an expansive number of measured confounders, we were unable to account for unmeasured confounding, as well; as such, we cannot draw inferences about the causal impact of school clinics on STI rates from our results. A related limitation was our inability to identify the mechanisms that were driving the statistically significant differences we found, which was beyond the scope of this manuscript. As well, because we do not have site-specific data describing the operation and school environment for each clinic, we were unable to explore how variations in clinic operations may have impacted our results.

\section{Conclusions}

Our results demonstrate that given their high STI and pregnancy rates, out-of-school youth are an important group to target, with respect to the provision of reproductive health services. Because of the differences in outcome measures found between those schools which have school-based clinics and those that do not, and because the school-based clinics vary from school to school (for example, in number of hours of operation) our comparisons cannot determine if the school based clinics have had an impact on the rates of STIs or pregnancies. In addition to the mixed evidence regarding whether or not provision of reproductive health services within schools can have an impact on reproductive health outcomes, further studies are needed on the effectiveness of youth-oriented clinics across a variety of school and community settings and other interventions to engage youth not involved with the school system. As well, research into understanding the trajectory of youth who fall out of the school system is also necessary, thus building better predictive models to inform interventions designed to engage with youth prior to dropping out of the school system. A holistic, comprehensive and systematic approach to prevention and intervention reproductive health services, with linkages among school-based clinics, community based teen clinics, and other outreach services for out of school youth should be emphasised.

\section{Additional file}

Additional file 1: Table S1: ICD-9 and ICD-10 codes used to define pregnancies. Table S2: Crude pregnancy and sexually transmitted infections rates, by enrolled/non-enrolled group and income quintile, 20002009. Table S3: Relative Rates of non-enrolled, by Income Quintile (Crude). (DOCX $18 \mathrm{~kb}$ )

\section{Abbreviations}

$95 \% \mathrm{Cl}, 95 \%$ confidence intervals; ICD, International Classification of Diseases; MCHP, Manitoba Centre for Health Policy; NSC, no school clinic; SC, school clinic; STI, sexually transmitted infections

\section{Acknowledgements}

PATHS Equity Team members: James Bolton; Marni Brownell; Charles Burchill; Elaine Burland; Mariette Chartier; Dan Chateau; Malcolm Doupe; Greg

Finlayson; Randall Fransoo; Chun Yan Goh; Milton Hu; Doug Jutte; Alan Katz; Laurence Katz; Lisa Lix; Patricia J. Martens^; Colleen Metge; Nathan C. Nickel; Colette Raymond; Les Roos; Noralou Roos; Rob Santos; Joykrishna Sarkar; Mark Smith; Carole Taylor; Randy Walld.

$\wedge$ deceased. 


\section{Funding}

This work was supported by the Canadian Institutes of Health Research (CIHR) and the Heart \& Stroke Foundation of Canada, under the program of research entitled "PATHS Equity for Children: a program of research into what works to reduce the gap for Manitoba's children." The authors acknowledge the Manitoba Centre for Health Policy for use of data contained in the Population Health Research Data Repository under project \# 2012 - 007 (HIPC \#2011/2012 - 24F). The results and conclusions are those of the authors and no official endorsement by MCHP, Manitoba Health or other data providers is intended or should be inferred. Data used in this study are from the Population Health Research Data Repository housed at MCHP, University of Manitoba and were derived from data provided by Manitoba Health, Healthy Living and Seniors; Vital Statistics, Manitoba Jobs and the Economy; Family Services; Manitoba Education and Advanced Learning; Statistics Canada; The Winnipeg Regional Health Authority; and Manitoba Housing and Community Development. Dr Patricia Martens wishes to acknowledge funding from the Canadian Institutes of Health Research (CIHR) and the Public Health Agency of Canada (PHAC) for her CIHR/PHAC Applied Public Health Research Chair (2008-2014). Dr Marni Brownell acknowledges the financial support of the Government of Manitoba through the Manitoba Center for Health Policy Population-Based Child Health Research Award. Dr Alan Katz acknowledges the support of the Manitoba Health Research Council and the Heart and Stroke Foundation for his Research Chair in Primary Prevention (2013-2018).

\section{Availability of data and materials}

Data will not be shared, as data contained in the Population Health Research Data Repository are housed under strict secure conditions. Agreements with the various trustees of the data restrict public access.

\section{Author's contributions}

SYS, CM, EB, MC, CC, AK, MB, RS, PJM made substantial contributions to the conception of the study. SYS wrote the first draft of the manuscript. CT was responsible for carrying out statistical analyses. LL, RS, JS, NCN and DC made substantial contributions to design of the study and contributed to data analysis. All authors critically reviewed drafts of the manuscript and provided intellectual content. All authors have approved this version of the manuscript.

\section{Competing interests}

The authors declare that they have no competing interests.

\section{Author details}

'Centre for Global Public Health, University of Manitoba, Winnipeg, Canada. 2Department of Community Health Sciences, University of Manitoba, Winnipeg, Canada. ${ }^{3}$ Centre for Healthcare Innovation, University of Manitoba, Winnipeg, Canada. ${ }^{4}$ Manitoba Centre for Health Policy, University of Manitoba, Winnipeg, Canada. ${ }^{5}$ Healthy Child Manitoba, Winnipeg, Canada.

\section{Received: 15 January 2016 Accepted: 16 June 2016}

\section{Published online: 21 June 2016}

\section{References}

1. Grunbaum JA, Kann L, Kinchen S, Ross J, Hawkins J, Lowry R, Harris WA, McManus T, Chyen D, Collins J. Youth risk behavior surveillance-United States, 2003. MMWR Surveill Summ. 2004;53:1-96.

2. Eaton DK, Kann L, Kinchen S, Shanklin S, Ross J, Hawkins J, Harris WA, Lowry R, McManus T, Chyen D, et al. Youth risk behavior surveillance-United States, 2007. MMWR Surveill Summ. 2008;57:1-131.

3. Santelli JS, Melnikas AJ. Teen fertility in transition: recent and historic trends in the United States. Annu Rev Public Health. 2010;31:371-83. 374 p following 383.

4. Gaudie J, Mitrou F, Lawrence D, Stanley FJ, Silburn SR, Zubrick SR. Antecedents of teenage pregnancy from a 14-year follow-up study using data linkage. BMC Public Health. 2010;10:63.

5. Public Health Agency of Canada. Report on Sexually Transmitted Infections in Canada: 2008. Ottawa: Public Health Agency of Canada; 2008.

6. Fothergill K, Ballard E. The school-linked health center: a promising model of community-based care for adolescents. J Adolesc Health. 1998;23:29-38.
7. Kirby D, Short L, Collins J, Rugg D, Kolbe L, Howard M, Miller B, Sonenstein F, Zabin LS. School-based programs to reduce sexual risk behaviors: a review of effectiveness. Public Health Rep. 1994;109:339-60.

8. Shepherd J, Kavanagh J, Picot J, Cooper K, Harden A, Barnett-Page E, Jones J, Clegg A, Hartwell D, Frampton GK, Price A. The effectiveness and costeffectiveness of behavioural interventions for the prevention of sexually transmitted infections in young people aged 13-19: a systematic review and economic evaluation. Health Technol Assess. 2010;14:1-206. iii-iv.

9. Kirby D, Waszak C, Ziegler J. Six school-based clinics: their reproductive health services and impact on sexual behavior. Fam Plann Perspect. 1991:23:6-16.

10. Carroll C, Lloyd-Jones M, Cooke J, Owen J. Reasons for the use and non-use of school sexual health services: a systematic review of young people's views. J Public Health (Oxf). 2012;34:403-10

11. Olsen JR, Cook PA, Forster S, Phillips-Howard PA. Accessibility of sexual health services in teenage sexual health service users: local area geospatial analysis. J Public Health (Oxf). 2012:34:438-46.

12. DeMatteo D, Major C, Block B, Coates R, Fearon M, Goldberg E, King SM, Millson M, O'Shaughnessy M, Read SE. Toronto street youth and HIV/AIDS: prevalence, demographics, and risks. J Adolesc Health. 1999;25:358-66.

13. Public Health Agency of Canada. Street Youth in Canada: Findings from Enhanced Surveillance of Canadian Street Youth 1999-2003. Ottawa: Public Health Agency of Canada; 2006.

14. Manlove J. The influence of high school dropout and school disengagement on the risk of school-age pregnancy. J Res Adolesc. 1998:8:187-220.

15. Nickel NC, Chateau DG, Martens PJ, Brownell MD, Katz A, Burland EM, Walld R, Hu M, Taylor CR, Sarkar J, et al. Data resource profile: Pathways to Health and Social Equity for Children (PATHS Equity for Children). Int J Epidemiol. 2014:43:1438-49.

16. Brownell MD, Roos NP, Roos LL. Monitoring health reform: a report card approach. Soc Sci Med. 2001;52:657-70.

17. Jutte $\mathrm{DP}$, Roos LL, Brownell MD. Administrative record linkage as a tool for public health research. Annu Rev Public Health. 2011:32:91-108.

18. Roos LL, Nichol JP. A research registry: uses, development, and accuracy. J Clin Epidemiol. 1999:52:39-47.

19. Roos LL, Menec VH, Currie RJ. Policy analysis in an information-rich environment. Soc Sci Med. 2004;58:2231-41.

20. Roos LL, Gupta S, Soodeen RA, Jebamani L. Data quality in an information-rich environment: Canada as an example. Can J Aging. 2005;24 Suppl 1:153-70.

21. Robinson JR, Young TK, Roos LL, Gelskey DE. Estimating the burden of disease. Comparing administrative data and self-reports. Med Care. 1997;35:932-47

22. Martens PJ, Chateau DG, Burland EM, Finlayson GS, Smith MJ, Taylor CR, Brownell MD, Nickel NC, Katz A, Bolton JM, Team PE. The effect of neighborhood socioeconomic status on education and health outcomes for children living in social housing. Am J Public Health. 2014;104:2103-13.

23. Nickel NC, Martens PJ, Chateau D, Brownell MD, Sarkar J, Goh CY, Burland E, Taylor C, Katz A. Have we left some behind? Trends in socio-economic inequalities in breastfeeding initiation: a population-based epidemiological surveillance study. Can J Public Health. 2014;105:e362-8.

24. Brownell MD, Nickel NC, Chateau D, Martens PJ, Taylor C, Crockett L, Katz A, Sarkar J, Burland E, Goh CY. Long-term benefits of full-day kindergarten: a longitudinal population-based study. Early Child Dev Care. 2014;185:291-316.

25. Centers for Disease Control and Prevention. Youth Risk Behavior Surveillance - United States, 2009. MMWR Surveill Summ. 2010;59:1-142.

26. Swartzendruber A, Zenilman JM, Niccolai LM, Kershaw TS, Brown JL, Diclemente RJ, Sales JM. It takes 2: partner attributes associated with sexually transmitted infections among adolescents. Sex Transm Dis. 2013;40:372-8.

27. Ford K, Sohn W, Lepkowski J. American adolescents: sexual mixing patterns, bridge partners, and concurrency. Sex Transm Dis. 2002;29:13-9.

28. Martens PJ, Bartlett J, Burland E, Prior H, Burchill C, Huq S, Romphf L, Sanguins J, Carter S, Bailly A. Health Inequities in Manitoba: is the Socioeconomic Gap in Health Widening or Narrowing Over Time? Winnipeg: Manitoba Centre for Health Policy; 2010

29. Brownell M, Chartier M, Santos R, Ekuma O, Au W, Sarkar J, MacWilliam L, Burland E, Koseva I, Guenette W. How are Manitoba's Children Doing? Winnipeg: Manitoba Centre for Health Policy; 2012

30. Fransoo R, Martens P, The Need To Know Team, Prior H, Burchill C, Koseva I, Bailly A, Allegro E. The 2013 RHA Indicators Atlas. Winnipeg: Manitoba Centre for Health Policy; 2013. 
31. Roos LL, Hiebert B, Manivong P, Edgerton J, Walld R, MacWilliam L, de Rocquigny J. What is most important: social factors, health selection, and adolescent educational achievement. Social Indicators Res. 2013:110:385-414

32. Martens P, Fransoo R, The Need To Know Team, Burland E, Prior H, Burchill C, Chateau D, Romphf L, Bailly A, Ouelette C. What Works? A First Look at Evaluating Manitoba's Regional Health Programs and Policies at the Population Level. Winnipeg: Manitoba Centre for Health Policy; 2008.

33. Mustard CA, Derksen S, Berthelot JM, Wolfson M, Roos LL. Age-specific education and income gradients in morbidity and mortality in a Canadian province. Soc Sci Med. 1997:45:383-97.

34. Brownell M, Santos R, Kozyrskyj A, Roos N, Au W, Dik N, Chartier M, Girard D, Ekuma O, Sirski M, et al. Next Steps in the Provincial Evaluation of the BabyFirst Program: Measuring Early Impacts on Outcomes Associated with Child Maltreatment. Winnipeg: Manitoba Centre for Health Policy; 2007.

35. Allen JP, Philliber $\mathrm{S}$. Who benefits most from a broadly targeted prevention program? Differential efficacy across populations in the teen outreach program. J Community Psychol. 2001;29:637-55.

36. Crosby RA, DiClemente RJ, Wingood GM, Salazar LF, Rose E, Sales JM. The protective value of school enrolment against sexually transmitted disease: a study of high-risk African American adolescent females. Sex Transm Infect. 2007:83:223-7.

37. Walker SC, Kerns SE, Lyon AR, Bruns EJ, Cosgrove TJ. Impact of School-Based Health Center use on academic outcomes. J Adolesc Health. 2010;46:251-7.

38. Van Cura M. The relationship between school-based health centers, rates of early dismissal from school, and loss of seat time. J Sch Health. 2010;80:371-7.

39. Kerns SE, Pullmann MD, Walker SC, Lyon AR, Cosgrove TJ, Bruns EJ. Adolescent use of school-based health centers and high school dropout. Arch Pediatr Adolesc Med. 2011;165:617-23.

40. Barnet B, Arroyo C, Devoe M, Duggan AK. Reduced school dropout rates among adolescent mothers receiving school-based prenatal care. Arch Pediatr Adolesc Med. 2004;158:262-8.

\section{Submit your next manuscript to BioMed Central and we will help you at every step:}

- We accept pre-submission inquiries

- Our selector tool helps you to find the most relevant journal

- We provide round the clock customer support

- Convenient online submission

- Thorough peer review

- Inclusion in PubMed and all major indexing services

- Maximum visibility for your research

Submit your manuscript at www.biomedcentral.com/submit

) Biomed Central 